\title{
usm

\section{Políticas de Avaliação e o Desenvolvimento Profissional do Professor de Ciências}

\author{
Assessment Policies and Professional Development of the Science \\ Teacher
}

Recebido em 26 de outubro de 2018

Paulo Sérgio Garcia

Universidade Municipal de São Caetano do Sul

Nelio Bizzo

Universidade de São Paulo

Sanny Silva da Rosa

Aprovado em 26 de março de 2019

Publicado em 18 de junho de 2019

\section{RESUMO:}

Este estudo analisa a percepção de professores de Ciências que atuam nos anos finais do ensino fundamental sobre seu desenvolvimento profissional, considerando as reformas nacionais realizadas na Educação das últimas décadas, sobretudo a implantação das Avaliações de Larga-Escala (ALEs). A teoria fundamentada foi usada como abordagem metodológica para coletar dados com esses profissionais $(N=77)$, na região do grande $A B C$ Paulista, uma das mais ricas do Brasil, situada na região metropolitana do estado de São Paulo. Os dados revelaram que, após a implantação das ALEs, a oferta de formação de professores se tornou ainda mais desregulada, afetando o desenvolvimento profissional dos professores de Ciências. Essas políticas têm estabelecido um contexto de inequidade de formação e de possibilidades profissionais dentro dos municípios, e o mais agravante, dentro da própria escola. Secretarias, Diretorias de Educação e escolas oferecem maiores oportunidades, recursos e tempos para a formação docente nas áreas de português e matemática. Esse quadro de desalinhamento da formação iniciou-se após a implementação das reformas nacionais. Os resultados desta pesquisa podem ser utilizados no contexto das universidades, nos cursos de formação de professores e diretores e junto às secretarias de educação.

Palavras-chave: Avaliação em Larga-Escala; Professores de Ciências; Desenvolvimento Profissional. 


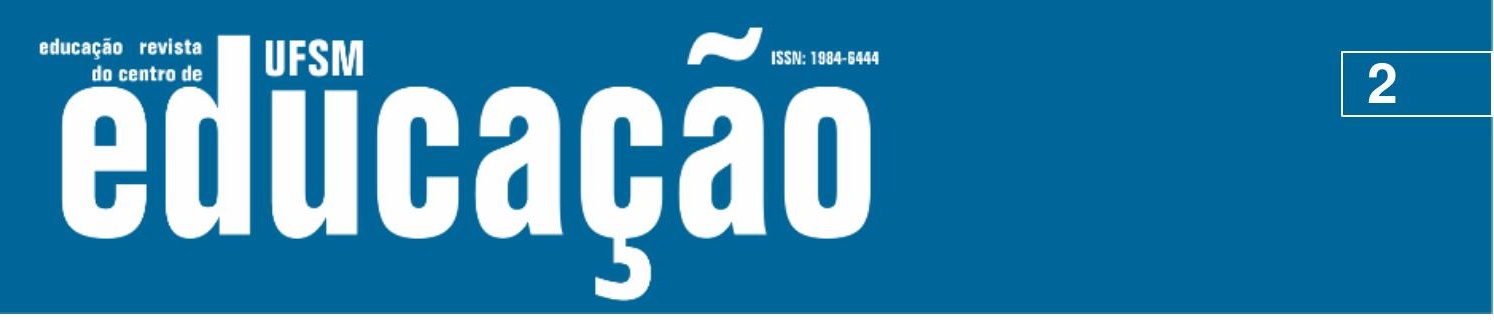

ISSN: 1984-6444 | http://dx.doi.org/10.5902/1984644435387

\section{ABSTRACT:}

This study analyzes the perception of science teachers who work in the final years of elementary education (students from 11 to 14 years old) on their professional development, considering the national reforms in Education of the last decades, especially the implementation of the Large-Scale Assessments (LEAs). The grounded theory was used as a methodological approach to collect data with these professionals $(\mathrm{N}=77)$, in the region of the great $A B C$ Paulista, one of the richest in Brazil, located in the metropolitan region of the state of São Paulo. The data revealed that, after the implementation of the LEAs, the provision of teacher education became even more deregulated, affecting the professional development of science teachers. These policies have established a context of inequality of teacher education and professional possibilities within the municipalities, and the most aggravating, within the school itself. Departments and Directories of education and schools are offering greater opportunities, resources and time for teacher education in the areas of Portuguese and mathematics. This misalignment of teacher education began after the implementation of the national reforms. The results of this research can be used in the context of universities, in the courses of teacher and principals' education and along to departments of education.

Keywords: Large-Scale Assessments; Science teachers; Professional development.

\section{Introdução}

O professor de Ciências desempenha um papel fundamental no desenvolvimento do pensamento científico, na formação do cidadão e nas mudanças sociais. Trata-se de um profissional que auxilia os alunos a refletirem sobre os fenômenos da natureza, sobre a ação do homem no meio ambiente e na sociedade. Ele também induz os jovens ao desenvolvimento de uma postura crítica, questionadora e investigativa (ALLCHIN, 2013; CHASSOT; OLIVEIRA, 2001) e favorece a compreensão de conceitos e os seus vínculos com as questões éticas implícitas nas relações entre Ciência, Sociedade e Tecnologia, com a crise ambiental, a destruição dos seres humanos, as questões do consumismo, o destino dos resíduos industriais e domésticos, a manipulação genética, entre outros (MACEDO; KATZKOWICZ, 2004; ALLCHIN, 2013).

No entanto, os professores de Ciências têm enfrentado vários desafios, entre eles o desinteresse dos alunos por essa área do conhecimento e, por consequência, 


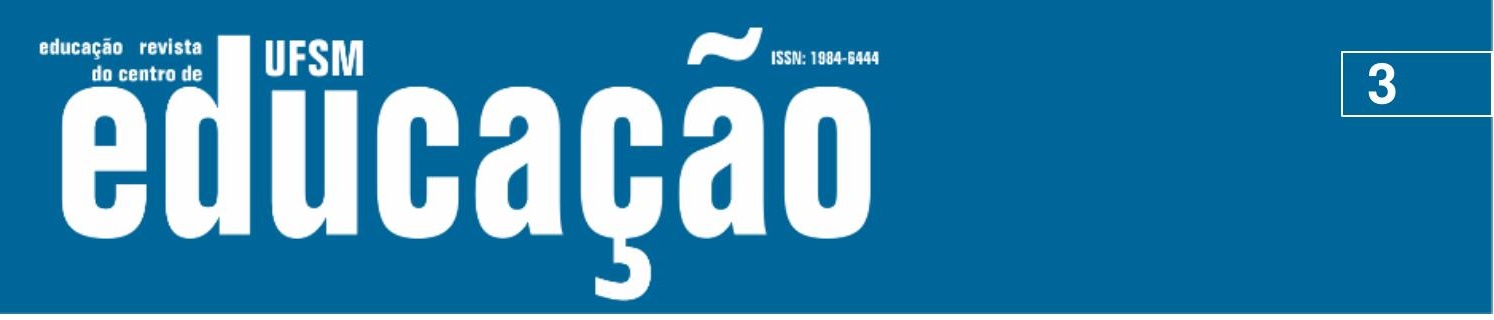

ISSN: 1984-6444 | http://dx.doi.org/10.5902/1984644435387

o baixo interesse do jovem em seguir carreiras científicas, (AIKENHEAD, 2005; BERNARDO et al., 2008; GOUW; BIZZO, 2006). Essa situação vem sendo ainda mais agravada pelas reformas educacionais que implementaram avaliações em largaescala, com foco exclusivo em português e matemática (PM), implementadas em muitos países em todo o mundo (SONGER; RUIZ-PRIMO, 2012; SMITH, 2014).

No Brasil, entre as muitas reformas nacionais que aconteceram desde o início dos anos 1990 (Lei de Diretrizes e Bases da Educação Nacional - LDBEN/96), assistimos a criação do Sistema Nacional de Avaliação da Educação Básica (SAEB), com o objetivo de avaliar a qualidade do ensino ministrado na educação básica.

No cenário educacional atual, o Brasil conta hoje, no ensino fundamental, com várias Avaliações em larga-escala que incidem sobre as disciplinas de português e matemática (Provinha Brasil, no segundo ano; Avaliação Nacional de Alfabetização, no terceiro; Prova Brasil, quinto e no nono). A qualidade da educação obrigatória tem sido monitorada com o auxílio do Índice de Desenvolvimento da Educação Básica (IDEB), criado em 2007, que combina o desempenho dos alunos, em PM, e o fluxo escolar.

Sousa e Bonamino (2013) sinalizaram que houve uma expansão dos testes, sobretudo após a criação do IDEB, em nível federal, estadual e municipal. De fato, como sinalizaram Bauer, Alavarse e Oliveira (2015), em um estudo realizado com 4.309 cidades, os municípios também estão criando seus próprios programas de avaliação baseados nas disciplinas de português e matemática.

Esse contexto, marcado exclusivamente por testes em PM, em geral, tem feito com que as escolas valorizem mais os resultados aferidos por esses indicadores (IDEB), pois a alta posição nesses rankings significa que a escola será muito mais reconhecida e valorizada pelos pais e pelas secretarias e diretorias de educação.

No entanto, já existe certo consenso quanto às limitações das ALEs e às consequências negativas desse modelo de avaliação sobre o trabalho das escolas, dos professores e a formação dos alunos. Autores sinalizam que elas ampliam a responsabilização, as punições e as injustiças na escola e na sociedade (FREITAS, 2013); induzem uma maior busca por resultados ao invés da melhoria da qualidade e da equidade educativa (IAIES, 2003); causam um empobrecimento curricular 


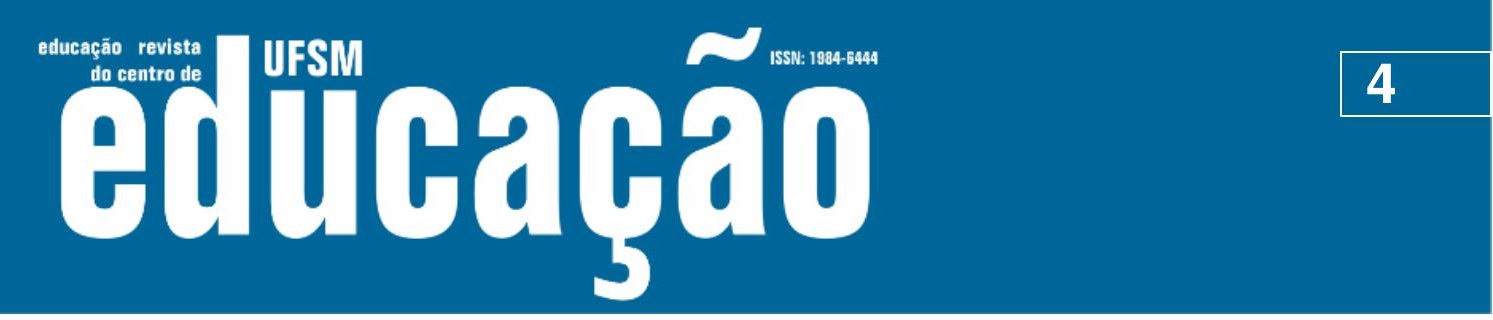

ISSN: 1984-6444 | http://dx.doi.org/10.5902/1984644435387

(MADAUS; RUSSEL; HIGGINS, 2009; GARCIA et al, 2018); fomentam maiores investimento dos gestores em recursos físicos e intelectuais voltados para as disciplinas de PM (GARCIA et al, 2018); inspiram um "novo" modelo de gestão educacional pública (gerencial); geram discussões quanto ao potencial dos testes para melhorar a qualidade do ensino (TEDESCO, 2003); induzem os sistemas, as escolas e os professores a destinarem maior tempo das aulas para ensinar os assuntos abordados nos exames, a treinar excessivamente os alunos para os testes nas disciplinas de PM, incentivando também a trapaça para melhorar as notas e a posição nos rankings (GARCIA et al, 2018).

Há também consequências dessas ALEs, especificamente, no ensino de Ciências. Estudos com professores desse componente curricular, realizados no Canadá, revelaram que os maiores recursos são destinados às áreas de Linguagem e Matemática, situação responsável pela desmotivação desses profissionais (FAZIO; KARROW, 2013). Ao mesmo tempo, essa disciplina não tem sido prioridade nas políticas de educação pública, nos programas educacionais, nas iniciativas escolares e na visão dos diretores das escolas (DOW, 2015).

Outras pesquisas, como as conduzidas por Clark e Linn (2003), concluíram que o tempo de instrução está fortemente correlacionado com a compreensão do aluno sobre conceitos científicos complexos. Os estudantes que têm poucas experiências consistentes e positivas com a ciência, porque a maior parte do tempo é dedicada às disciplinas de português e matemática, podem estar perdendo oportunidades de desenvolver habilidades de raciocínio científico necessárias para iniciar o interesse fundacional pela ciência (BLANK, 2013; FITZGERALD; DAWSON; HACKLING, 2013). Esses são indícios de que os fortes investimentos apenas nessas duas áreas trazem consequências significativas para o desenvolvimento do ensino de Ciências e para o (des)interesse dos alunos pelos conhecimentos científicos.

No Brasil, as consequências das ALEs, entre outras questões, têm induzido os alunos a acreditarem que as disciplinas mais importantes na escola são as de português e matemática, percepção que é reforçada pelos professores, pelas escolas e secretarias de educação (GARCIA et al, 2018a). De algum modo, essa situação 


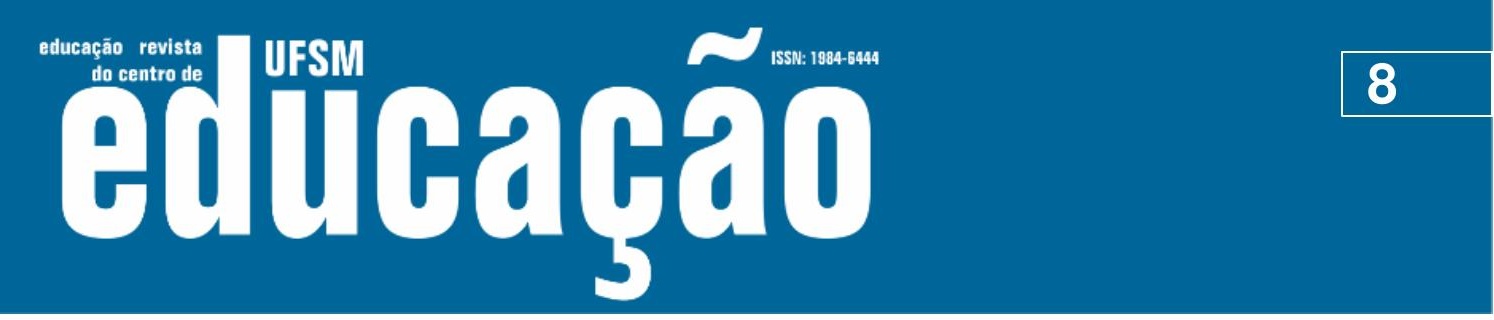

ISSN: 1984-6444 | http://dx.doi.org/10.5902/1984644435387

A terceira perspectiva trata o desenvolvimento profissional atrelado à compreensão pessoal. Nesse sentido, o desenvolvimento do professor "envolve muito mais do que mudar os seus comportamentos - envolve toda a pessoa que o professor é" (OLIVEIRA-FORMOSINHO, 2009, p. 231).

Oliveira-Formosinho (2009) apresenta alguns modelos de desenvolvimento profissional: modelo autônomo atrela-se ao entendimento de que os docentes aprendem sozinhos, autonomamente, mas de forma individual, a partir de leituras, pesquisas e estudos ou na experimentação de diferentes estratégias de ensino, entre outros; modelo baseado nos processos de observação associa-se à observação do trabalho do docente por outro professor a fim de melhorar a prática pedagógica; centrado no desenvolvimento curricular/organizacional ou baseado em projetos, refere-se à organização e à realização de uma determinada tarefa ou algum tipo de problema; baseado em cursos de formação, onde ocorre a aquisição de conhecimentos ou de competências; centrado na investigação para a ação, associado ao interesse do professor ou de um grupo, que selecionam estratégias para uma pesquisa.

Sintetizando, o desenvolvimento profissional docente se traduz pela continuidade da formação inicial, é decorrente das múltiplas experiências vividas pelos docentes que acontecem na vida, na escola e nos relacionamentos. Existem três perspectivas do desenvolvimento profissional docente (desenvolvimento de conhecimentos e de competências, a mudança ecológica e aquele atrelado à compreensão pessoal) e alguns modelos de desenvolvimento profissional (autônomo, processos de observação, centrado no desenvolvimento curricular/organizacional, baseado em cursos de formação, centrado na investigação para a ação).

\section{Região do Grande ABC}

A região do $A B C$ Paulista é uma área industrial, parte da área metropolitana de São Paulo. Sua sigla vem das três cidades que originalmente formavam a região: Santo André (SA), São Bernardo do Campo (SBC) e São Caetano do Sul (SCS). 


\section{تulloapẫ

ISSN: 1984-6444 | http://dx.doi.org/10.5902/1984644435387

média das cidades, São Caetano possuía $R$ \$2.349,00; Santo André $R$ \$ 1.499,00; São Bernardo R\$ 1.394,00; Ribeirão Pires R\$ 974,00; Diadema R\$ 917,00; Mauá R\$ 815,00 e Rio Grande R\$ 747,00 (OBSERVATÓRIO DE EDUCAÇÃO, 2015).

Quanto ao número de escolas e matrículas, o Quadro 01 apresenta uma síntese do Ensino Fundamental:

Quadro 01: Número de escolas e matrículas

\begin{tabular}{|c|c|c|c|c|}
\hline Município & \multicolumn{2}{|c|}{ N. de escolas } & \multicolumn{2}{c|}{ N. de matrículas } \\
\hline & Estadual & Municipal & Estadual & Municipal \\
\hline Santo André & 86 & - & 23.724 & - \\
\hline São Bernardo & 72 & - & 30.383 & - \\
\hline São Caetano & 10 & 21 & 2.328 & 5.298 \\
\hline Diadema & 57 & - & 19.809 & - \\
\hline Mauá & 63 & - & 17.602 & - \\
\hline Ribeirão Pires & 29 & 09 & 4.045 & 879 \\
\hline Rio Grande da Serra & 11 & - & 2.052 & - \\
\hline
\end{tabular}

Fonte: Censo Escolar 2017.

Conforme o Censo Escolar, de 2017, a região tinha 328 escolas de ensino fundamental estaduais e 30 municipais. Neste contexto, as primeiras atendiam 99.943 estudantes e as segundas 6.177 jovens. A situação do IDEB do ensino fundamental, anos finais, das cidades, esfera estadual e municipal, é revelada no Quadro 02:

Quadro 02: IDEB observado - 2015 e 2017

\begin{tabular}{|c|c|c|c|c|c|c|}
\hline Município & \multicolumn{3}{|c|}{ Esfera Municipal } & \multicolumn{3}{c|}{ Esfera Estadual } \\
\hline Município & $\mathbf{2 0 1 3}$ & $\mathbf{2 0 1 5}$ & $\mathbf{2 0 1 7}$ & $\mathbf{2 0 1 3}$ & $\mathbf{2 0 1 5}$ & $\mathbf{2 0 1 7}$ \\
\hline Santo André & - & - & - & 4,2 & 4,5 & 4,9 \\
\hline São Bernardo & - & - & - & 4,5 & 4,6 & 4,9 \\
\hline São Caetano & 5,3 & 6,0 & 6,4 & 4,9 & 5,2 & 5,5 \\
\hline Diadema & - & - & - & 4,5 & 5,2 & 5,5 \\
\hline Mauá & 4,0 & 3,9 & 4,3 & 4,4 & 4,7 & 5,0 \\
\hline Ribeirão Pires & 5,4 & 5,4 & 5,7 & 4,8 & 5,1 & 5,4 \\
\hline Rio Grande da Serra & - & - & - & 4,2 & 4,6 & 5,0 \\
\hline
\end{tabular}

Fonte: Censo Escolar 2017.

As aferições têm revelado avanços no IDEB dos municípios da região, tanto na esfera municipal como na estadual. Apesar deste crescimento ser discreto em alguns casos (Mauá esfera municipal), ele vem ocorrendo nas cidades do grande $A B C$ 


\section{Tusm

ISSN: 1984-6444 | http://dx.doi.org/10.5902/1984644435387

implementação das políticas de avaliação em larga escala, com foco exclusivo em português e matemática.

Os professores de Ciências que participaram deste estudo eram de escolas municipais e estaduais dos sete municípios da região do grande $A B C$. O Quadro 03 mostra os dados:

Quadro 03: localização dos professores de Ciências

\begin{tabular}{|c|c|c|}
\hline Município & $\begin{array}{c}\text { Esfera } \\
\text { municipal }\end{array}$ & $\begin{array}{c}\text { Esfera } \\
\text { estadual }\end{array}$ \\
\hline São Caetano & 26 & 10 \\
\hline Ribeirão Pires & 4 & 4 \\
\hline Mauá & - & 3 \\
\hline Santo André & - & 10 \\
\hline São Bernardo & - & 14 \\
\hline Diadema & - & 4 \\
\hline Rio Grande & - & 2 \\
\hline
\end{tabular}

Fonte: Elaboração dos autores.

A análise envolveu, no início, uma codificação aberta para, em seguida, realizar uma segmentação dos dados com o intuito de produzir conceitos subjacentes. Um processo de análise consistente que visa apreciar as padronizações das informações, identificar as diferenças e iniciar o trabalho de inferência sobre o conjunto de dados coletados pelos pesquisadores.

Os conceitos advindos dessas primeiras análises foram, então, considerados à luz de pontos comuns e divergentes para formar as categorias deste estudo, usando as indicações já estabelecidas pela teoria fundamentada (CORBIN; STRAUSS, 1998). As categorias emergentes foram consideradas em relação às semelhanças e diferenças para produzir subcategorias.

A categorização dos dados foi realizada a partir da análise das variáveis pessoais: sexo, idade, formação, experiência no magistério e carga horária; e aquelas relacionadas ao desenvolvimento profissional do professor: condições de trabalho, utilização de recursos financeiros e intelectuais, criação de materiais, elaboração de projetos (reforço escolar, professor substituto), utilização do tempo (reuniões, formação contínua e encontros) e atuação dos coordenadores pedagógicos. 


\section{Tusm Aitlathat

ISSN: 1984-6444 | http://dx.doi.org/10.5902/1984644435387

A apreciação das informações, a constatação de vários padrões de similaridade e, sobretudo, a pouca divergência entre as enunciações dos professores, das várias cidades, permitiram que os dados fossem agrupados de forma geral, o que enriqueceu as análises e os entendimentos sobre o fenômeno estudado, possibilitando uma compreensão sobre as cidades e, ao mesmo tempo, sobre a região.

\section{Resultados}

Os professores de Ciências que participaram deste estudo tinham, em média, 40 anos de idade ( $D P=9.6$ ); perto de $80 \%$ eram do sexo feminino; todos possuíam Licenciatura em Ciências, com credenciais para atuar no ensino fundamental e, em média, eram profissionais com 24 anos de experiência no magistério ( $D P=7.3$ ).

As respostas dos professores apresentaram muitas similaridades, independente da cidade analisada. Mais de $90 \%$ dos participantes sinalizaram as precárias condições dos laboratórios de Ciências, indicando que muitos eram usados como um local (depósito) para guardar objetos, cadeiras e carteiras ou não apresentavam os materiais necessários, como substâncias e vidros, para a realização de experiências. Um professor afirmou "eu nunca usei o laboratório desta escola e se tiver de usar eu nem sei como" (Professor_04). Outro profissional sinalizou que "nunca pisei no laboratório de Ciências, que vive fechado, usado como depósito de sei lá o que. Eu acho que seria bom dar aulas lá tanto para os alunos quanto para mim também. Eu poderia aprender muitas coisas lá" (Professor_32).

Esse processo, de acordo com esses profissionais, de notória desvalorização, começou a se agravar ainda mais depois que as escolas passaram a ser avaliadas e os professores de português e matemática considerados como decisivos neste processo: "tudo passou a girar em torno de português e matemática, por causa do bônus. Ficou desmotivador para o professor que dá aula de Ciências" (Professor_6). Uma situação que de fato "se iniciou depois das provas do governo". (Professor_49).

Os profissionais entrevistados sinalizaram, sobretudo aqueles que atuavam no município de São Caetano do Sul, que os maiores recursos financeiros e intelectuais 


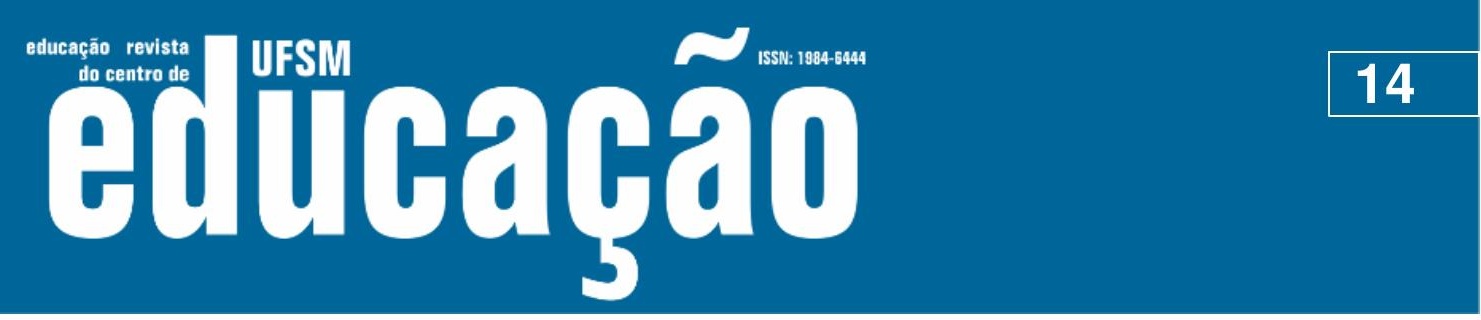

ISSN: 1984-6444 | http://dx.doi.org/10.5902/1984644435387

das Secretarias de Educação estavam sendo utilizados para a criação de projetos, programas, ações, iniciativas e cursos nas áreas de português e matemática.

No primeiro caso, sobre a questão financeira, quase $80 \%$ dos professores de Ciências indicaram que os docentes de PM tinham muito mais recursos, em termos de materiais (papel, recursos de impressão, tinta) para preparar os alunos para as aulas, para a Prova Brasil ou para o Sistema de Avaliação de Rendimento Escolar do Estado de São Paulo (Saresp). Como um professor de Ciências mencionou: "para essas duas áreas, o diretor libera a impressão de exercícios, compra, por exemplo, software e jogos de matemática ou livros didáticos ou de literatura para os alunos aprenderem melhor português e, por outro lado, não temos nada em nossos laboratórios de ciências" (Professor_40).

Os professores indicaram, ainda, que a compra de softwares, livros, materiais didáticos e jogos eram muito maiores nessas duas áreas. Em termos de jogos, em 2017 e 2018, estava em curso, em três cidades (São Caetano do Sul, Santo André e São Bernardo), um projeto chamado "Mind Lab" (com custo médio de $\$ 500$ mil reais, apurado no setor de vendas da empresa), com o objetivo de desenvolver o raciocínio lógico e de colaborar com o ensino da matemática. Esses três municípios utilizavam também a plataforma Khan Academy (projeto de uma ONG educacional criada com a missão de fornecer educação de alta qualidade para qualquer um, em qualquer lugar, a partir do uso de vídeos), em 2016, 2017 e 2018, com o objetivo de melhorar a aprendizagem e o rendimento dos alunos em matemática e português. A esse respeito, um professor indicou que os maiores "gastos são com os professores de português e matemática. As outras disciplinas ficam de escanteio" (Professor_67).

Na segunda questão, sobre os recursos intelectuais, na cidade de São Caetano do Sul havia uma avaliação local denominada de Prova São Caetano, que avaliava os estudantes dos quintos e nonos anos do ensino fundamental nas disciplinas de português e matemática. Em algumas edições das provas, foram avaliados também os jovens dos quartos e oitavos anos. Segundo o depoimento de um professor: "quando a prova São Caetano utiliza conhecimentos somente de português e matemática, já está claro o que a Secretaria de Educação valoriza. Ciências, é certo, não está neste rol" (Professor_05). 


\section{Fism Autlatato

ISSN: 1984-6444 | http://dx.doi.org/10.5902/1984644435387

acompanhada de um certificado, que permite ao docente somar alguns pontos e progredir na carreira. Trata-se, para o docente, de uma atualização em seus conhecimentos e, ao mesmo tempo, um aumento em seu pagamento.

Em geral, os maiores recursos das Secretarias de Educação e das Diretorias de Ensino têm sido alocados para o desenvolvimento de projetos nas áreas de português e matemática. Maiores investimentos têm sido endereçados aos professores dessas disciplinas. Fazio e Karrow (2013) encontraram situação similar na região de Ontário, no Canadá, demonstrando que parece não se tratar de um fenômeno local.

Nesse contexto, os professores de português e matemática dispunham de muito mais tempo de reuniões com os diretores ou com os coordenadores pedagógicos em encontros formativos, mais formação continuada em termos de cursos, workshops, entre outros, o que Blank (2013) e Dow (2015) reportaram no cenário americano e canadense.

No cenário brasileiro, Mira e Cartaxo (2014) e um estudo do Observatório da Educação (2017) tinham relatado que as temáticas mais dominantes na formação docentes eram aquelas atreladas às áreas de português e matemática, possibilitando maiores oportunidades para esses profissionais.

Por fim, é preciso denunciar que este contexto, com maiores oportunidades para os docentes de PM e de desmotivação dos professores de Ciências, pode reduzir ainda mais o interesse dos alunos pelo ensino de Ciências, em geral, e em buscar as carreiras científicas, em particular (AIKENHEAD, 2005; BERNARDO et al., 2008). Uma situação que pode também, entre outras coisas, afetar o desenvolvimento do pensamento crítico, questionador e investigativo dos nossos alunos (BULUNUZ; JARRETT, 2010; CHASSOT; OLIVEIRA, 2001).

\section{Considerações finais}

Neste estudo foi analisado a percepção dos professores de Ciências sobre o seu desenvolvimento profissional, considerando as reformas nacionais que implementaram as avaliações em larga-escala. 


\section{T.tusn

ISSN: 1984-6444 | http://dx.doi.org/10.5902/1984644435387

As análises indicaram que essas políticas, que estão induzindo as escolas na busca de melhores resultados nos indicadores (IDEB e IDESP), têm estabelecido um contexto de inequidade de formação e de possibilidades profissionais dentro das cidades e, ainda mais agravante, dentro das próprias escolas. As ALEs estão desalinhando ainda mais a formação dos professores e limitando o desenvolvimento profissional dos professores de Ciências. Na região do grande $A B C$, essa formação está sendo oferecida desproporcionalmente aos professores de português e matemática, o que afeta o desenvolvimento profissional dos professores de Ciências.

Essas políticas têm induzido as Secretarias de Educação, as Diretorias de Ensino e as escolas a oferecerem mais oportunidades, recursos e tempo para a formação contínua para os professores de PM. Aquisições de materiais, criação de projetos e investimentos são maiores para esses profissionais, causando um desalinhamento na formação docente, uma situação começou a ocorrer após a criação e a implementação das avaliações em larga-escala.

Neste contexto, algumas consequências estão sendo contabilizadas: professores de Ciências estão ficando, cada vez mais, desmotivados, estão aprendendo e se atualizando menos quanto aos conhecimentos gerais e específicos e, acima de tudo, as reformas acontecidas nas últimas décadas relacionadas às avaliações têm afetado a questão do desenvolvimento profissional desses docentes.

\section{Referências}

AIKENHEAD, Glen. Research Into STS Science Education. Educación Química, v. 16, p. 384-397, 2005.

ALLCHIN, Douglas. Teaching the nature of science: perspectives \& resources. Saint Paul: SHiPS Education Press. 2013.

BALL, Stephen J. Profissionalismo, gerencialismo e performatividade. Cad. Pesqui., São Paulo, v. 35, n. 126. p. 539-564, 2005.

BALL, Stephen J. The Education Debate. London: Policy Press, 2008. 


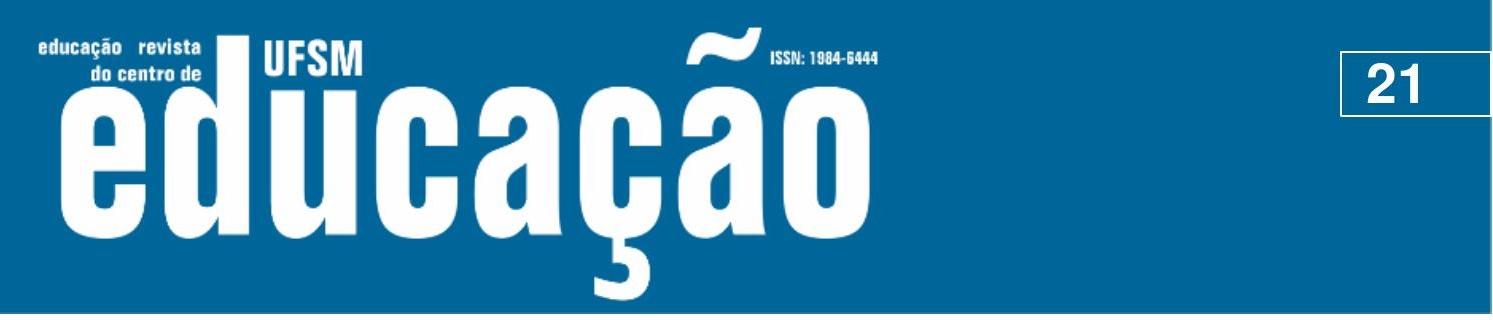

ISSN: 1984-6444 | http://dx.doi.org/10.5902/1984644435387

BAUER, Adriana; ALAVARSE, Ocimar Munhoz; OLIVEIRA, Romualdo Portela. Avaliações em larga escala: uma sistematização do debate. Educação e Pesquisa, São Paulo, v. 41, n. especial, p. 1367-1382, 2015.

BERNARDO, Allan.; LINJAP, Auxencia; PRUDENTE, Maricar; ROLEDA, Lydia. Students' perceptions of science classes in the Philippines. Asia Pacific Education Review, v. 9, n. 3, p. 285-295, 2008.

BIZZO, Nelio. Pensamento Científico: a natureza da ciência no ensino fundamental. São Paulo: Melhoramentos, 2012.

BLANK, Rolf. K. Science instructional time is declining in elementary schools: What are the implications for student achievement and closing the gap? Science Education, V. 97, n. 6, p. 830-847, 2013.

BONAMINO, Alicia. C. de. Avaliação educacional no Brasil 25 anos depois: onde estamos? In: BAUER, A.; GATTI, B. A. (Org.). Vinte e cinco anos de avaliação de sistemas educacionais no Brasil: implicações nas redes de ensino, no currículo e na formação de professores. Florian.: 2013. p. 43-60.

BROOKE, Nigel; CUNHA, Maria Amália; FALEIROS, Matheus. A avaliação externa como instrumento da gestão educacional nos estados: relatório final. Belo Horizonte: Game/UFMG; Fundação Victor Civita, 2011. Disponível em: Acesso em: 27 dez. 2012.

BULUNUZ, Mizrap; JARRETT, Olga, S. Developing an interest in science: Background experiences of preservice elementary teachers. International Journal of Environmental and Science Education, v. 5, n. 1, p. 65-84, 2010.

CANDAU, Vera. Maria. Currículo, didática e formação de professores: uma teia de ideias força e perspectivas de futuro. In: OLIVEIRA, M. R. N. S.; PACHECO, J. A.(orgs.) Currículo, didática e formação de professores. $1^{a}$. ed. Campinas, SP: Papirus, 2013. p. 7-20.

CLARK, Douglas; LINN, Marcia, C. Designing for knowledge integration: The impact of instructional time. The Journal of the Learning Sciences, v. 12, n. 4, p. 451-493, 2003.

CHASSOT, Attico; OLIVEIRA, Renato Jose. (orgs). Ciência, Ética e Cultura na Educação. São Leopoldo: Ed. UNISINOS. 1988.

CASASSUS, Juan. Política y metáforas: un análisis de la evaluación estandarizada en el contexto de la política educativa. In: BAUER, Adriana; GATTI, Bernardete A.;TAVARES, Marialva R. (Org.). Vinte e cinco de avaliação de sistemas educacionais no Brasil: origens e pressupostos. Florianópolis: Insular, 2013. p. 21-46. 


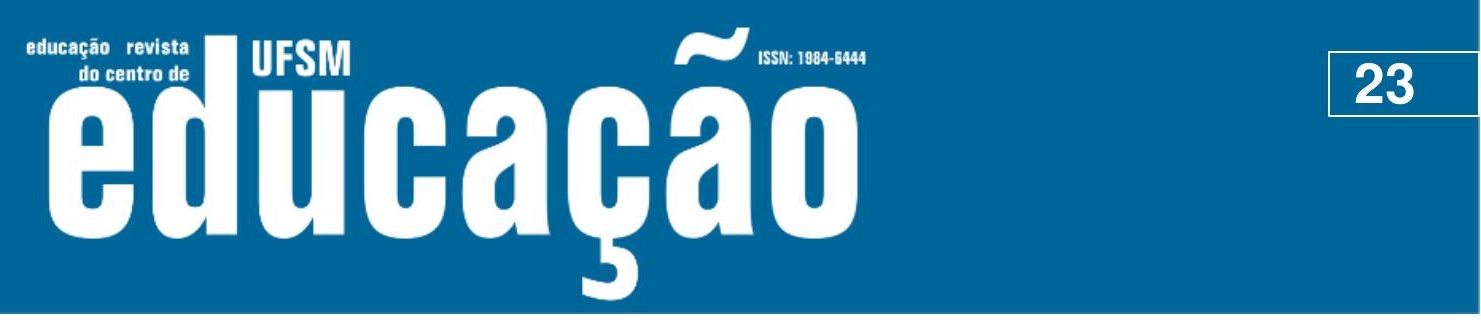

ISSN: 1984-6444 | http://dx.doi.org/10.5902/1984644435387

HAGOPIAN, Jesse. (Ed.). More than a score: the new uprising against high-stakes testing. Chicago: Haymarket Books, 2014.

HOBOLD, Márica Souza. Desenvolvimento profissional dos professores: aspectos conceituais e práticos. Práxis Educativa, Ponta Grossa, v. 13, n. 2, p. 425-442, 2018.

IAIES, Gustavo. Evaluar las evaluaciones. In: IAIES, G. et al. Evaluar las evaluaciones: una mirada política acerca de las evaluaciones de la calidad educativa. Buenos Aires: Unesco/IIPE, 2003. p. 15-36.

MADAUS, George; RUSSELL, Michael; HIGGINS, Jennifer. The paradoxes of high stakes testing: how they affect students, their parents, teachers, principals, schools, and society. Charlotte: Information Age, 2009.

MACEDO, Beatriz; KATZDOWICZ, Raquel. Educação científica sim, mas qual e como? IN MACEDO, B (org) Cultura Científica, um direito de todos. Brasília: OREALC, p. 65-84, 2004.

MARCELO, Carlos. Desenvolvimento profissional docente: passado e futuro. Sísifo Revista de Ciências da Educação, Lisboa, n. 8, p. 7-22, 2009.

MIRA, Marilia Marques; CARTAXO, Simone Regina. M. Formação continuada no ensino fundamental: implicações das avaliações de rendimento escolar. XVII Endipe

- Encontro Nacional de Didática e Prática de Ensino. 2014.

OBSERVATÓRIO da Educação do Grande ABC. Relatório do primeiro trimestre. Universidade Municipal de São Caetano do Sul. 2015.

OBSERVATÓRIO da Educação do Grande ABC. Relatório do primeiro trimestre. Universidade Municipal de São Caetano do Sul. 2017.

OLIVEIRA, Romualdo Portela. A utilização de indicadores de qualidade na unidade escolar ou porque o IDEB é insuficiente. In: BAUER, Adriana; GATTI, Bernardete A. (Org.). Vinte e cinco anos de avaliação de sistemas educacionais no Brasil: implicações nas redes de ensino, no currículo e na formação de professores. Florianópolis: Insular, 2013. p. 87-100.

OLIVEIRA-FORMOSINHO, Julia Desenvolvimento profissional dos professores. In: FORMOSINHO, J. (Coord.). Formação de professores: aprendizagem profissional e acção docente. Portugal: Porto Editora, 2009. p. 221-284.

SANTOS, Lucíola L. A avaliação em debate. In: BAUER, Adriana; GATTI, Bernardete A. (Org.). Vinte e cinco anos de avaliação de sistemas educacionais no Brasil: origens e pressupostos. Florianópolis: Insular, 2013. p. 229-245. 


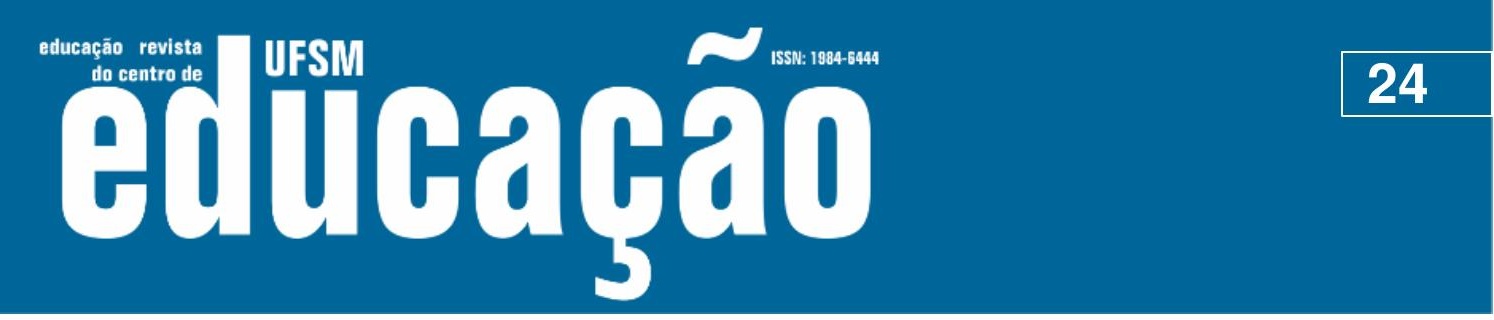

ISSN: 1984-6444 | http://dx.doi.org/10.5902/1984644435387

SOUSA, Sandra Zakia. Avaliação externa e em larga escala no âmbito do Estado brasileiro: interface de experiências estaduais e municipais de avaliação da educação básica com iniciativas do governo federal. In: BAUER, Adriana; GATTI, Bernardete A. (Org.). Vinte e cinco anos de avaliação de sistemas educacionais no Brasil: implicações nas redes de ensino, no currículo e na formação de professores. Florianópolis: Insular, 2013. p. 61 - 85.

STECHER, Brian. M. Consequences of large-scale, high-stakes testing on school and classroom practice. In: HAMILTON, Laura; STECHER, Brian M.; KLEIN, Stephen P. (Ed.). Making sense of test-based accountability in education. Santa Monica: Rand, 2002. p. 79-100.

TEDESCO, Juan. C. Prólogo. In: IAIES, G. et al. Evaluar las evaluaciones: una mirada política acerca de las evaluaciones de la calidad educativa. Buenos Aires: Unesco/IIPE, 2003. p. 11-14.

\section{Correspondência}

Paulo Sérgio Garcia - Professor dos cursos de pós-graduação da Universidade Municipal de São Caetano do Sul. Coordenador do Observatório de Educação do Grande ABC Paulista.

Nelio Bizzo - Professor Titular Senior de Metodologia de Ensino de Ciências Biológicas da Faculdade de Educação da Universidade de São Paulo.

Sanny Silva da Rosa - Professora dos cursos de pós-graduação da Universidade de São Caetano do Sul.

Universidade Municipal de São Caetano do Sul. Av. Goiás, 3.400. São Caetano do Sul 09550-05, São Paulo, Brasil.

E-mail: paulo.garcia@uscs.edu.br -bizzo@usp.br -professorasanny@gmail.com

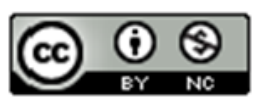

This work is licensed under a Creative Commons Attribution-NonCommercial 4.0 International (CC BY-NC 4.0) 